\title{
Environmental protection: reactive and proactive approaches
}

\author{
Subhas Sikdar ${ }^{1}$ \\ Published online: 4 December 2018 \\ c) Springer-Verlag GmbH Germany, part of Springer Nature 2018
}

A recent Chemical \& Engineering News article (2018) provided data to show that we have failed miserably to recycle plastics wastes, according to a 2016 report of the World Economic Forum. Out of 78 million metric tons of plastics packaging produced globally, $40 \%$ goes to landfills, $32 \%$ is discarded to the environment, and only $14 \%$ is collected for recycling. Out of this $14 \%, 4 \%$ gets lost, $8 \%$ is recycled to lower-quality products, and only $2 \%$ is recycled for reuse for same or equivalent products. A quarter of a century ago, Take Back regulations in Europe caused producers in Europe to collect used plastic parts and incinerate them to produce energy for use. Carbon dioxide was simply released to the atmosphere. This practice counted as "recycling." Landfilling being prohibitively expensive, and plastics recycling technologies not being available, especially for thermoplastics, merely reducing them to invisible gases was acceptable. Other problems loom as well. Nowadays, microplastics dispersion in water is an aquatic ecological concern. The proliferating use of exotic nanoparticles in plastics mix has created additional concern about health impacts when widely dispersed in the environment. In the face of all the pronouncements on plastics recycling over many years, this has to be accepted as a pitiful performance.

In the days when pollution prevention was a favorite goal in all sectors of the economy, and in academia, one core principle used to be: begin with the end in mind, when designing a product or a process. While the principle sometimes worked through avoidance of undesirable toxic materials in product formulation, anticipating an undesirable impact in the future was difficult. The infamous Bhopal disaster resulting from faulty design could, of course, be anticipated and prevented. Good intentions go awry when after years of use we find that we failed to anticipate the ill effects of a product. For example, tetraethyl lead was invented to prevent

Subhas Sikdar-Editor in Chief.

Subhas Sikdar

subhas.sikdar@gmail.com

1 Cincinnati, OH, USA knocking in internal combustion engines, leading to the proliferation of automobile ownership, or the introduction of inert chlorofluorocarbons as refrigerants. In both cases one societal good was exchanged for another adverse environmental impact, as revealed later when much damage was already done. This was reversed by banning lead in gasoline altogether, a practice that gradually spread throughout the world, and the chlorofluorocarbons were phased out by an international treaty. Other times, even when the inkling of an impending problem is suspected, anticipation of potential problems yielded to convenience, such as when we replaced tetraethyl lead with methyl tertiary butyl ether, the use of which led to groundwater pollution from leaky underground gasoline tanks. Governance of any kind is subject to concerns of economic hardships of the people, and even when the knowledge is at hand, the will to impose it may not be present. Thus, as the public is made aware of the adverse impacts of a product or practice, we end up with a reactive approach to environmental stewardship. This reactionary approach has served us well, when we consider the salutary effects of appropriate regulations on air and water. There has been suffering, of course, until the cleanup. The victims of the famous London fog did not escape the hardship, but later generations were definitely helped.

In recent times, there is much interest in inherently safe (or safer) products. This noble goal is still subject to anticipating future ills. Niels Bohr famously said, it is difficult to predict, especially the future. There are sometimes "known unknowns" but are difficult to measure or quantify, and "unknown unknowns" (or hidden variables) which plague us only in later years after the products are in the market place for some time. In short, we don't know what we don't know. Meanwhile, innovations march on.

This perplexing situation is exemplified by the need for rare earths, those lanthanide and actinide series metals that are not really rare but are not distributed evenly throughout the earth's crust. Rare earth materials in tiny amounts are essential to the products of information technology, and to wind mill parts and solar panels. Vast amounts of earth would have to be processed to recover these very valuable 
materials. The USA does not possess needed rare earth resources; many of these, such as yttrium, neodymium, europium, terbium, and dysprosium, are considered strategic or critical to the economy, because of which reserves are maintained by the government as an insurance against supply disruption. Tiny amounts of these rare earth materials are dispersed widely through the products of high technology today, and we don't have a handle on their environmental impacts. Pollution prevention approach would not have been effective in this situation because of crucial lack of knowledge of environmental toxicity. Hence, these products cannot yet be described as inherently safe. Perhaps in the future we will find out the ill effects of these, if any, and the only recourse would be the reactive approach.

There is not one preferred approach to environmental protection. Both prevention and control technologies should be considered when a potential problem has been discovered.

With this issue of Clean Technologies and Environmental Policy, we are entering our third decade of publication, having just proudly completed 20 years of publishing a broad spectrum of cleaner technology approaches and the policies that either are influenced by them or are the source causes.
We started with just four issues per year at the outset and steadily increased the number of issues to ten as of last year. This is a commendable growth that we carefully managed, without going overboard. I want to take this opportunity to thank the editors, members of the editorial board, and the silent members of the publication office and its management for conducting themselves with integrity, efficiency, and diligence. The quality of the journal critically depends on competent reviewers. Hundreds of them have helped us in making sure that the quality passes the peer-review tests. We are grateful to them. We are now looking forward to improving upon the quality even more.

\section{Reference}

C\&E News, June 18, 2018, p 24

Publisher's Note Springer Nature remains neutral with regard to jurisdictional claims in published maps and institutional affiliations. 